\title{
Phorbol Ester Effects at Hippocampal Synapses Act Independently of the $\gamma$ Isoform of PKC
}

\author{
Yukiko Goda, ${ }^{1,3}$ Charles F. Stevens, ${ }^{1}$ and Susumu Tonegawa ${ }^{2}$ \\ ${ }^{1}$ Howard Hughes Medical Institute \\ The Salk Institute \\ La Jolla, California 92037 \\ ${ }^{2}$ Howard Hughes Medical Institute \\ Center for Cancer Research and Department of Biology \\ Massachusetts Institute of Technology \\ Cambridge, Massachusetts 02139
}

\begin{abstract}
$\mathrm{Ca}^{2+}$ /phospholipid-dependent protein kinase has long been thought to play an important role in modulating synaptic efficacy. It has been shown previously that mice lacking the brain-specific $\gamma$ subtype of PKC display abnormal long-term potentiation (LTP), whereas ordinary synaptic transmission is unaffected by the mutation. We now examine the effects of phorbol esters, which are nonselective activators of PKC, on synaptic modulation in these mutant mice. In wild-type mice, phorbol esters produce marked enhancement of synaptic transmission that is largely presynaptic in origin, an effect that has been thought to share mechanisms with LTP. In mutant mice, phorbol ester-mediated potentiation is normal despite the absence of the major PKC isoform. As in wild-type mice, this synaptic enhancement is at least partly attributable to presynaptic changes. Our results demonstrate that the $\gamma$ isotype of PKC is not essential for phorbol ester-mediated synaptic facilitation, and place limitations on the possible roles of PKC in LTP.
\end{abstract}

\section{Introduction}

Long-term potentiation (LTP) is a long-lasting enhancement of excitatory synaptic transmission

\footnotetext{
${ }^{3}$ Corresponding author.
}

that is thought to underlie certain forms of learning and memory (see Bliss and Collingridge 1993). LTP is expressed robustly in the hippocampus where $\mathrm{Ca}^{2+}$ /phospholipid-dependent protein $\mathbf{k i -}$ nase (PKC) is highly abundant. An important role for this kinase family in the mechanisms of LTP has been proposed based on the following evidence. Injection of exogenous PKC into hippocampal pyramidal neurons elicits synaptic potentiation that is reminiscent of LTP (Hu et al. 1987), and a subcellular redistribution of PKC accompanies the onset of LTP (Akers et al. 1986; Angenstein et al. 1994). In addition, inhibition of postsynaptic PKC blocks the induction of LTP (Reymann et al. 1988; Malenka et al. 1989; Malinow et al. 1989; Wang and Feng 1992; Hvalby et al. 1994), and under certain conditions maintenance of LTP is also reversed by relatively specific inhibitors of PKC (Klann et al. 1991; Sacktor et al. 1993). PKC may thus be involved in various stages of LTP.

An alternative approach to studying the role of PKC in synaptic plasticity has been to characterize the stimulatory effects of PKC activity on synaptic transmission. Application of phorbol esters, which are selective activators of PKC, causes marked potentiation of synaptic responses in the hippocampus (Malenka et al. 1987; Yamamoto et al. 1987; Parfitt and Madison 1993; Capogna et al. 1995). Whether this phorbol ester-mediated synaptic potentiation reveals the participation of PKC in LTP has been much debated. In one study, phorbol esters were found to potentiate synaptic transmission in a manner indistinguishable from LTP in that, following maximal synaptic enhancement by phorbol esters, LTP could no longer be elicited (Malenka et al. 1986; also see Hvalby et al. 1988).

LEARNING \& MEMORY 3:182-187 (c) 1996 by Cold Spring Harbor Laboratory Press ISSN1072-0502/96 \$5.00

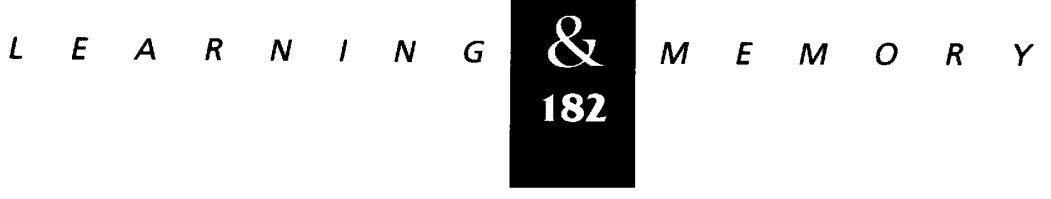


In another study, however, phorbol ester-mediated synaptic potentiation was transient-unlike LTP which is, by definition, maintained-and application of phorbol ester did not occlude LTP completely (Gustafsson 1988; Muller et al. 1988). Thus, it remains to be seen whether a PKC involvement in LTP engages the same set of molecular events initiated by phorbol ester application.

PKC constitutes a family of isoenzymes; at least nine distinct PKC isoforms have been identified to date (for review, see Hug and Sarre 1993). Currently available PKC inhibitors and activators, however, cannot distinguish among different isotypes of the kinase, and consequently we know very little of the role of specific PKC isoforms in synaptic plasticity. To investigate the requirement for the $\gamma$ isoform of PKC in modulating synaptic strength, Abeliovich et al. (1993a,b) have generated mice homozygous for the disruption of the gene encoding PKC $\gamma$. The $\gamma$ isoform was chosen because it is brain-specific, is the dominant isoform in the hippocampus (Huang et al. 1987; Nishizuka 1988), and appears late in development so that the likelihood of obtaining mice with developmental brain defects is minimized. Behavioral and initial electrophysiological characterization of PKC $\gamma$ mutant mice have been reported (Abeliovich et al. 1993a,b). Briefly, these mice are viable and display no gross anatomical abnormalities. Synaptic transmission is also normal in mutant mice, and two forms of synaptic plasticity, pairedpulse facilitation and long-term depression, are indistinguishable from that of wild-type mice. LTP, however, is altered in mice lacking the $\gamma$ isoform of PKC. We sought to test whether phorbol estermediated synaptic enhancement is affected in these mice, and therefore to evaluate the possible role for the $\gamma$ isoform in the phorbol ester effects that have been compared to LTP.

\section{Materials and Methods}

\section{CELL CULTURE AND SIICE PREPARATION}

Cell culture of hippocampal neurons was prepared from E15-E17 embryos of wild-type (C57Bl/ 6) or PKC $\gamma$ knockout mice as described previously (Geppert et al. 1994). Cells were plated at a density of $6 \times 10^{4}$ to $7 \times 10^{4}$ cells $/ \mathrm{ml}$ and grown in Basal Media Eagle (Gibco BRL) containing 10\% fetal calf serum, $1 \mathrm{~mm}$ sodium pyruvate, $20 \mathrm{~mm}$ D-glucose, $\mathrm{Mito}^{+}$serum extender (Becton Dickinson, Bedford, MA), and penicillin/streptomycin
(Gibco BRL). Cell cultures were used for recording 9-13 days after plating. Standard procedures were used to prepare transverse hippocampal slices $(350 \mu \mathrm{m}$ in thickness) from wild-type or mutant mice (male or female, mostly 1-3 months old) as described (Abeliovich et al. 1993a).

\section{ELECTROPHYSIOLOGY}

Cell cultures were used exclusively for wholecell patch clamp recordings from paired cells using Axopatch 200 (Axon Instruments, Burlingame, CA). Presynaptic cell held at $-70 \mathrm{mV}$ was stimulated by a $1 \mathrm{msec}$ step pulse to $+20 \mathrm{mV}$. Subsequent generation of an action potential in the unclamped axon resulted in synaptic current recorded from the adjacent postsynaptic cell. Signals were filtered at $2 \mathrm{kHz}$, digitized at $5 \mathrm{kHz}$, and analyzed with programs written in AXOBASIC. External recording solution consisted of $137 \mathrm{~mm}$ $\mathrm{NaCl}, 5 \mathrm{~mm} \mathrm{KCl}, 3 \mathrm{~mm} \mathrm{CaCl}, 2 \mathrm{~mm} \mathrm{MgCl}_{2}, 10 \mathrm{~mm}$ D-glucose, $5 \mathrm{~mm}$ HEPES-NaOH (pH 7.3) and 100 $\mu \mathrm{M}$ picrotoxin. When recording spontaneous Miniature Excitatory Post Synaptic Currents (mepsc) $0.5 \mu \mathrm{M}$ tetrodotoxin was included in the bath solution to prevent spontaneous firing of neurons. The tips of patch pipette were filled with the following solution: $150 \mathrm{~mm}$ potassium methyl sulfate, $5 \mathrm{~mm} \mathrm{KCl}, 10 \mathrm{~mm}$ EGTA, $10 \mathrm{~mm}$ HEPES-KOH, (pH 7.2). The electrodes were backfilled with the same solution plus $2 \mathrm{~mm}$ ATP, $10 \mathrm{~mm}$ creatine phosphate, $25 \mathrm{U} / \mathrm{ml}$ rabbit skeletal muscle creatine phosphokinase (Calbiochem, La Jolla, CA), $0.5 \mathrm{~mm}$ GTP and $2 \mathrm{mM} \mathrm{MgCl}_{2}$. Field-potential recordings from hippocampal slices were carried out as described (Abeliovich et al. 1993a).

Phorbol esters (Biomol, Plymouth Meeting, PA) were prepared as $10 \mathrm{~mm}$ stock solution in DMSO, and diluted in extracellular solution to 10 $\mu \mathrm{M}$ immediately before application. For experiments monitoring the effects of phorbol esters on mepscs in dissociated cultures, phorbol diacetate (PDAc) was used at $2 \mu \mathrm{M}$. DMSO at $0.1 \%$ (highest concentration tested) had no effect on basal synaptic transmission.

\section{Results}

Phorbol esters cause reversible enhancement of synaptic transmission in cultures of dissociated hippocampal neurons (Segal 1989; Finch and Jackson 1990); our first goal, therefore, was to deter-

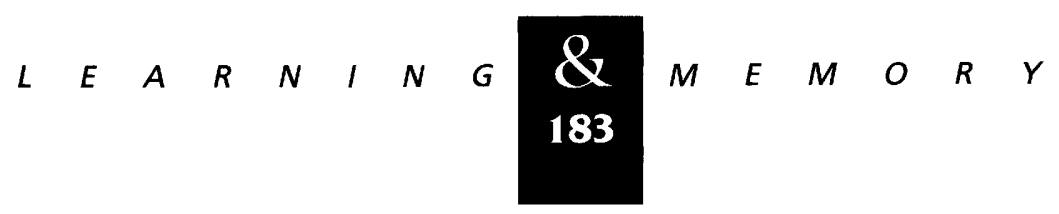


mine if phorbol esters potentiate synaptic transmission in PKC $\gamma$ mutant mice. Low-density cultures of hippocampal pyramidal neurons were prepared from PKC $\gamma$ mutant mice, and whole-cell patch clamp recordings were carried out with pairs of cells isolated on an island of substrate (Geppert et al. 1994). Stimulation of the presynaptic cell reliably evoked postsynaptic responses in the other member of a mutant neuron pair. Application of $10 \mu \mathrm{M}$ phorbol diacetate (PDAc), but not inactive phorbol, rapidly increased synaptic responses reversibly in the absence of PKC $\gamma$, just as it does in wild-type cultures [Figure 1 and data not shown; average potentiation was $210 \pm 18 \%$ ( \pm S.E.M.) of the baseline values in $n=5$ mutant cells, and $190 \pm 40 \%$ ( \pm S.E.M.) in $n=8$ wild type cells]. The $\gamma$ isotype of PKC is, therefore, not essential for phorbol ester-mediated potentiation.

To determine whether PDAc acts pre- or postsynaptically we monitored postsynaptic responses (mepsc) to spontaneously released single quanta of neurotransmitters. If phorbol esters act postsynaptically by increasing the sensitivity of neurotransmitter receptors to released transmitter molecules, for example, then one would expect to see an increase in mepsc size. If, however, the effect of phorbol esters is presynaptic, the frequency of spontaneous release may increase whereas mepsc amplitude should remain unaltered. Figure $2 \mathrm{~A}$ displays typical mepsc recordings

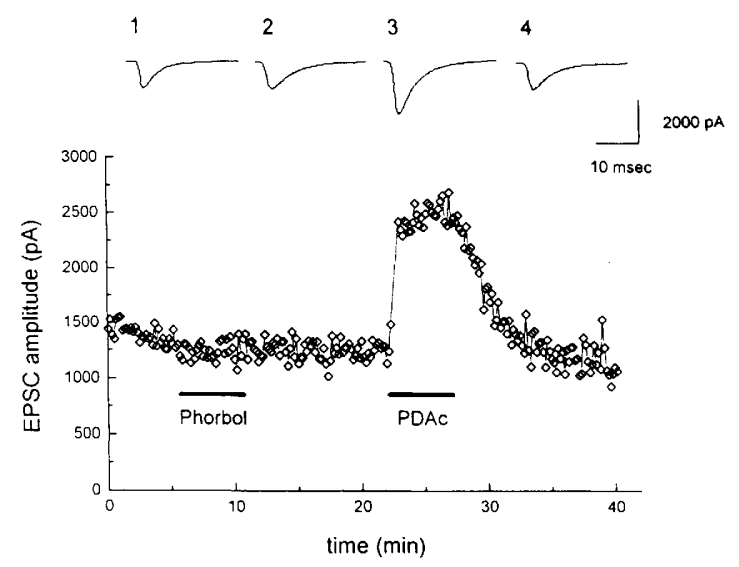

Figure 1: Phorbol ester effect on synaptic transmission between a pair of hippocampal neurons in dissociated culture prepared from PKC $\gamma$ mutant mice. Application of $10 \mu \mathrm{M}$ PDAc but not $10 \mu \mathrm{M}$ phorbol reversibly increases EPSC amplitude as shown in this example cell. Presynaptic cell was stimulated every $10 \mathrm{sec}$. Typical traces obtained during the baseline recording (1), phorbol application (2), PDAc application (3), and after PDAC washout (4) are shown at the top. from PKC $\gamma$ mutant cultures before and during 2 $\mu \mathrm{M}$ PDAc application. As expected from the presynaptic effects of phorbol esters on wild-type cells (Malenka et al. 1987; Yamamoto et al. 1987; Segal 1989; Finch and Jackson 1990; Parfitt and Madison 1993; Capogna et al. 1995) mepsc frequency increased three- to fourfold upon application of PDAc (Fig. 2A,B), whereas the amplitude distribution of mepsc remained largely unchanged [Fig. 2C; data not shown ( $n=6$ mutant cells)]. As in wild-type cells the synaptic enhancement caused by phorbol esters reflects increased probability of transmitter release.

Almost all PKC isotypes are activated by phorbol esters in vitro except for PKC $\zeta$ which exhibits constitutive kinase activity (Hug and Sarre 1993). Cells lacking the $\gamma$ isotype could still exhibit phorbol ester-mediated enhancement of transmitter release if other isoforms could substitute for the missing PKC $\gamma$. Because PKC $\gamma$ is the predominant PKC isotype in the hippocampus (Huang et al. 1987; Sae et al. 1988), the absence of this particular isotype in mutant animals might well be expected to result in smaller potentiation. Therefore, to evaluate the magnitude of the phorbol ester effect, we compared the extracellular field responses recorded from PDAc-treated hippocampal slices obtained from wild-type and PKC $\gamma$ mutant mice. The rationale for using hippocampal slices as opposed to cultured neurons is that extracellular field recordings enable one to follow responses from large populations of neurons so that the average response to PDAc can be obtained for each experiment. Figure 3 shows cumulative histograms of synaptic potentiation caused by $10 \mu \mathrm{M}$ PDAc application. There is no significant difference in the distribution of synaptic PDAc-produced enhancement between 13 wild-type and 15 mutant slices $(P \geqslant 0.2$; Kolmogorov-Smirnoff twosample test). Because biochemical analysis of brain extracts demonstrates that two other major isotypes of PKC, $\alpha$ and $\beta$, are not overexpressed in the mutant animals (Abeliovich et al. 1993a), the intact PDAc effect cannot reflect a compensatory increase in the quantities of these other isoforms. PKC $\gamma$, therefore, is likely to be a minor player, at most, in mediating presynaptic phorbol ester effects.

\section{Discussion}

Abeliovich et al. (1993a) have demonstrated previously that mice lacking the functional form of 

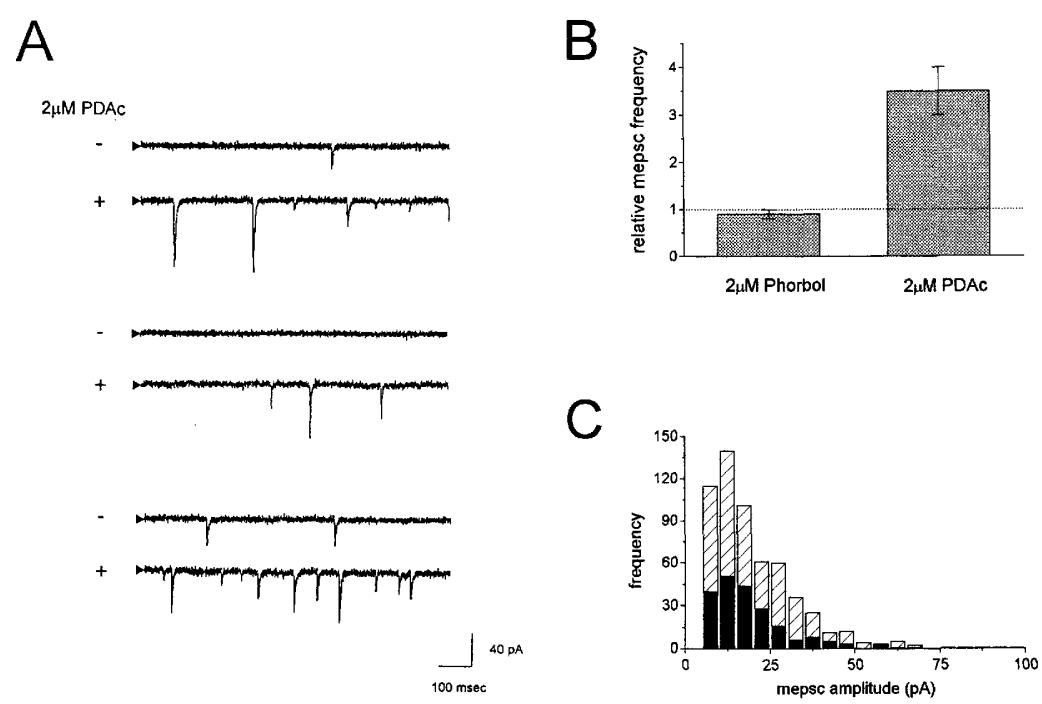

Figure 2: (A) PDAC $(2 \mu \mathrm{M})$ increases the rate of spontaneous transmitter release two- to sixfold in PKC $\gamma$ mutant cultures. Three representative experiments are shown. The external recording solution included $0.5 \mu \mathrm{M}$ TTX. (B) Summary of relative increase in mepsc frequency during application of $2 \mu \mathrm{M}$ phorbol $(0.9 \pm 0.1$; $n=3$ cells) or $2 \mu \mathrm{M}$ PDAc $(3.5 \pm 0.5 ; n=6$ cells) compared with baseline mepsc frequency in PKC $\gamma$ mutant cultures. The error bars represent \pm S.E.M. (C) Amplitude histograms of mepscs before (solid bars) and during (hatched bars) $2 \mu \mathrm{M}$ PDAc application obtained from a representative PKC $\gamma$ mutant cell.

PKC $\gamma$ express altered LTP, indicating that PKC $\gamma$ is somehow involved in LTP. Nevertheless, PKC $\gamma$ is not necessary for LTP because LTP comparable to that observed in wild-type mice could be generated in mutant mice under special conditions. PKC $\gamma$, therefore, may either be an essential component of LTP whose absence is readily compensated for by activation of other second messenger pathways or may be a component of the regulatory machinery that modulates LTP. Alternatively, PKC $\gamma$ may be unrelated to LTP such that its absence results in, for example, some developmental defect that affects LTP indirectly. The nonessential function of PKC $\gamma$ is much like the nonobligatory

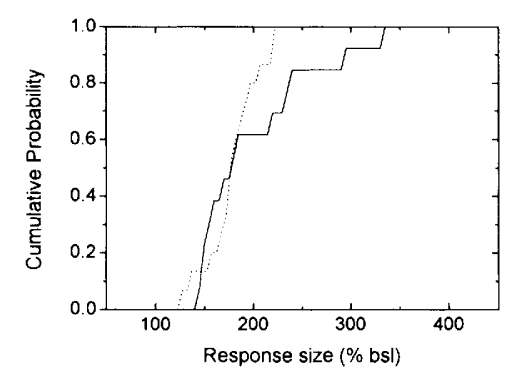

Figure 3: Cumulative probability distributions of peak PDAc response size, represented as the percentage of the baseline response, are shown for field potential recordings from 13 wild-type (solid line; mean $=199 \pm 16 \%$, \pm S.E.M.) and 15 mutant slices (dotted line; mean $=179 \pm 8 \%$, \pm S.E.M.). The two distributions are not significantly different $(P>0.2$; Kolmogorov-Smirnoff two-sample test). PDAc $(10 \mu \mathrm{M})$ increases synaptic response just as effectively in the absence of PKC $\gamma$ as compared with wild-type slices. nature of the enhancement in synaptic strength produced by phorbol esters on LTP.

Four straightforward possible interpretations of these observations-both phorbol ester-mediated increase in synaptic strength and functional PKC $\gamma$ are dispensable for LTP_-are as follows (Fig. 4). (1) PKC $y$ is involved in LTP and phorbol esters invoke the PKC action in LTP. With this possibility, it is clear that PKC $\gamma$ is not the relevant kinase isoform stimulated by phorbol esters for LTP, and thus the altered LTP observed in the mutant animals would be an indication of some general regulatory mechanism served by the $\gamma$ isoform for LTP. (2) PKC $\gamma$ plays an essential role in LTP, but the phorbol ester effect might be irrelevant for LTP. The simplest version of this alternative is unlikely to be true because phorbol esters should effectively activate PKC including the $\gamma$ isoform, and thus should have implications for LTP production if $\mathrm{PKC} \gamma$ is centrally involved in this process. (3) PKC $\gamma$ activity may be irrelevant for LTP (the altered LTP in the knockout animals would reveal

$$
\text { required for LTP? }
$$

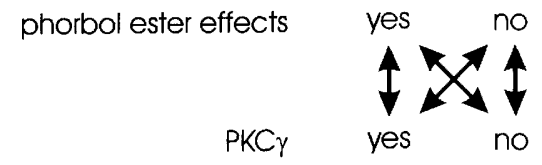

Figure 4: Four possible combinations for interpreting the role of phorbol ester effects and PKC $\gamma$ on LTP. See text for explanation. 


\section{Goda et al.}

some general regulatory defect as pointed out above), but phorbol esters could still engage steps (ones not involving PKC $\gamma$ ) that lead to LTP. Were this the case, the phorbol esters would act through PKC isoforms other than $\gamma$ or some target other than PKCs altogether. This possibility is consistent with the observation that PKC inhibitor, $\mathrm{H} 7$, does not completely inhibit the phorbol ester effect on synaptic transmission (O'Dell et al. 1991; Y. Goda and C. Stevens, unpubl.). Proteins such as munc $13 s$ do contain domains that are homologous to the phorbol ester binding region of PKC yet lack kinase activity (Maruyama and Brenner 1991; Brose et al. 1995); the properties of these proteins may be modified upon phorbol ester binding to influence/regulate LTP. (4) It could be that neither PKC $\gamma$ nor phorbol ester-activated pathways are responsible for LTP induction and/or maintenance and the effects of the phorbol esters on synaptic transmission are tangential to the LTP production pathway. Our data cannot distinguish between these possibilities, but places constraints on all of them, as just noted.

The experiments described here reveal that the phorbol ester effect at hippocampal synapses is distinct from ordinary LTP in that it does not require the $\gamma$ subtype of PKC. The involvement of PKCs in LTP must be a rather complex series of steps possibly taking place at both the pre- and postsynaptic terminals. Only with further spatially and temporally controlled knockout animals and better pharmacological agents is this question to be finally settled.

\section{Acknowledgments}

We thank Asa Abeliovich for the PKC $\gamma$ mutant mice. This work was supported by Howard Hughes Medical Institute (S.T. and C.F.S.), Shionogi Institute for Medical Science (S.T.), National Institutes of Health grant 5 RO1 NS 12961-17 (C.F.S.), and Young Investigator Award from the National Alliance for Research on Schizophrenia and Depression (Y.G.).

The publication costs of this article were defrayed in part by payment of page charges. This article must therefore be hereby marked "advertisement" in accordance with 18 USC section 1734 solely to indicate this fact.

\section{References}

Abeliovich, A., C. Chen, Y. Goda, A.J. Silva, C.F. Stevens, and S. Tonegawa. 1993a. Modified hippocampal long-term potentiation in PKC $y$-mutant mice. Cell 75: 1253-1262.

Abeliovich, A., R. Paylor, C. Chen, J. Kim, J. Wehner, and
S. Tonegawa. 1993b. PKC $\gamma$-mutant mice exhibit moderate deficits in contextual learning. Cell 75: 1263-1271.

Akers, R.F., D.M. Lovinger, P.A. Colley, D.J. Linden, and A. Routtenberg. 1986. Translocation of protein kinase $C$ activity may mediate hippocampal long-term potentiation. Science 231: $587-589$.

Angenstein, F., G. Riedel, K.G. Reymann, and S. Staak. 1994. Hippocampal long-term potentiation in vivo induces translocation of protein kinase C $\gamma$. NeuroReport 5: 381-384.

Bekkers, J.M. and C.F. Stevens. 1991. Excitatory and inhibitory autaptic currents in isolated hippocampal neurons maintained in cell culture. Proc. Natl. Acad. Sci. 88: 7834-7838.

Bliss, T.V.P. and G.L. Collingridge. 1993. A synaptic model of memory: Long-term potentiation in the hippocampus. Nature 361: 31-39.

Brose, N., K. Hofmann, Y. Hata, and T.C. Südhof. 1995. Mammalian homologues of Caenorhabditis elegans unc-13 gene define novel family of $\mathrm{C}_{2}$-domain proteins. I. Biol. Chem. 270: 25273-25280.

Capogna, M., B.H. Gähwiler, and S.M. Thompson. 1995. Presynaptic enhancement of inhibitory synaptic transmission by protein kinase $\mathrm{A}$ and $\mathrm{C}$ in the rat hippocampus in vitro. J. Neurosci. 15: 1249-1260.

Finch, D.M. and M.B. Jackson. 1990. Presynaptic enhancement of synaptic transmission in hippocampal cell cultures by phorbol esters. Brain Res. 518: 269-273.

Geppert, M., Y. Goda, R.E. Hammer, C. Li, T.W. Rosahl, C.F. Stevens, and T.C. Südhof. 1994. Synaptotagmin I: A major $\mathrm{Ca}^{2+}$ sensor for transmitter release at a central synapse. Cell 79: 717-727.

Gustafsson, B., Y.-Y. Huang, and H. Wigström. 1988. Phorbol ester-induced synaptic potentiation differs from long-term potentiation in the guinea pig hippocampus in vitro. Neurosci. Lett. 85: 77-81.

Hu, G.Y., Ø. Hvalby, S.I. Walaas, K.A. Albert, P. Skjeflo, P. Andersen, and P. Greengard. 1987. Protein kinase C injection into hippocampal pyramidal cells elicits features of long term potentiation. Nature 328: 426-429.

Huang, F.L., Y. Yoshida, H. Nakabayashi, and K.-P. Huang. 1987. Differential distribution of protein kinase $C$ isozymes in the various regions of brain. J. Biol. Chem.

262: 15714-15720.

Hug, H. and T.F. Sarre. 1993. Protein kinase C isozymes: Divergence in signal transduction. Biochem. J. 291: 329-343.

Hvalby, Ø., K. Reymann, and P. Andersen. 1988. Intracellular analysis of potentiation of CA1 hippocampal synaptic transmission by phorbol ester application. Exp. Brain. Res. 71: 588-596. 


\section{PHORBOL ESTER EFFECTS IN PKC $\gamma$ MUTANT MICE}

Hvalby, Ø., H.C. Hemmings, O. Paulsen, A.J. Czernik, A.C. Nairn, J.-M. Godfraind, V. Jensen, M. Raastad, J.F. Storm, P. Andersen, and P. Greengard. 1994. Specificity of protein kinase inhibitor peptides and induction of long-term potentiation. Proc. Natl. Acad. Sci. 91: 4761-4765.

Klann, E., S.J. Chen, and J.D. Sweatt. 1991. Persistent protein kinase activation in the maintenance phase of long-term potentiation. J. Biol. Chem. 266: 24253-24256.

Malenka, R.C., D.V. Madison, and R.A. Nicoll. 1986. Potentiation of synaptic transmission in the hippocampus by phorbol esters. Nature 321: 175-177.

Malenka, R.C., G.S. Ayoub, and R.A. Nicoll. 1987. Phorbol esters enhance transmitter release in rat hippocampal slices. Brain Res. 403: 198-203.

Malenka, R.C., J.A. Kauer, D.J. Perkel, M.D. Mauk, P.T. Kelly, R.A. Nicoll, and M.N. Waxham. 1989. An essential role for postsynaptic calmodulin and protein kinase activity in long-term potentiation. Nature 340: 554-557.

Malinow, R., H. Schulman, and R.W. Tsien. 1989. Inhibition of postsynaptic PKC or CaMKII blocks induction but not expression of LTP. Science 245: 862-866.

Maruyama, I.N. and S. Brenner. 1991. A phorbol ester/diacylglycerol-binding protein encoded by the unc-13 gene of Caenorhabditis elegans. Proc. Natl. Acad. Sci. 88: $5729-5733$.

Muller, D., P.-A. Buchs, Y. Dunant, and G. Lynch. 1990. Protein kinase $\mathrm{C}$ activity is not responsible for the expression of long-term potentiation in the hippocampus. Proc. Natl. Acad. Sci. 87: 4073-4077.

Nishizuka, Y. 1988. The molecular heterogeneity of protein kinase $C$ and its implications for cellular regulation. Nature 334: 661-665.

O'Dell, T., E.R. Kandel, and S.G.N. Grant. 1991. Long-term potentiation in the hippocampus is blocked by tyrosine kinase inhibitors. Nature 353: 558-560.

Parfitt, K.D. and D.V. Madison. 1993. Phorbol esters enhance synaptic transmission by a presynaptic, calcium-dependent mechanism in rat hippocampus. J. Physiol. 471: 245-268.

Reymann, K.G., R. Brödemann, H. Kase, and H. Matthies. 1988. Inhibitors of calmodulin and protein kinase $\mathrm{C}$ block different phases of long-term potentiation. Brain Res.

461: 388-392.

Sacktor, T.C., P. Osten, H. Valsamis, X. Jiang, M.U. Naik, and $E$. Sublette. 1993. Persistent activation of the $\zeta$ isoform of protein kinase $C$ in the maintenance of long-term potentiation. Proc. Natl. Acad. Sci. 90: 8342-8346.

Sae, K., N. Saito, M.S. Shearman, U. Kikkawa, Y. Ono, K. Igarashi, C. Tanaka, and Y. Nishizuka. 1988. Distinct cellular expression of $\beta 1$ and $\beta 2$ subspecies of protein kinase $C$ in rat cerebellum. J. Neurosci. 8: 3850-3856.

Segal, M. 1989. Synaptic transmission between cultured rat hippocampal neurons is enhanced by activation of protein kinase C. Neurosci. Lett. 101: 169-174.

Wang, J.H. and D.P. Feng. 1992. Postsynaptic protein kinase $\mathrm{C}$ essential to induction and maintenance of long-term potentiation in the hippocampal CA1 region. Proc. Natl. Acad. Sci. 89: 2576-2580.

Yamamoto, C., M. Higashima, and S. Sawada. 1987. Quantal analysis of potentiating action of phorbol ester on synaptic transmission in the hippocampus. Neurosci. Res. 5: $28-38$.

Received June 25, 1996; accepted in revised form June 26, 1996.

$$
\begin{array}{lllllllllllllllll}
L & E & A & R & N & I & N & G & \mathbf{Q}_{\mathbf{1}} & M & E & M & O & R & Y
\end{array}
$$




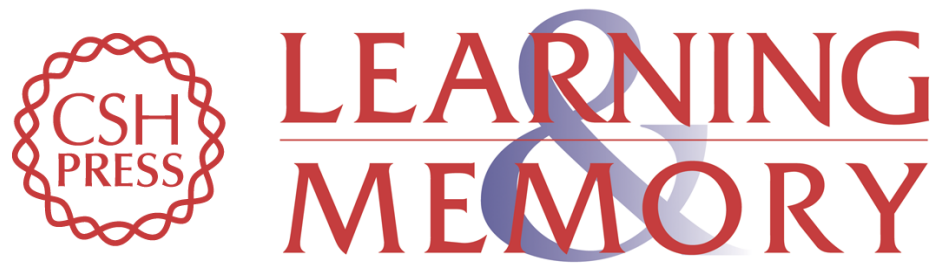

Phorbol ester effects at hippocampal synapses act independently of the gamma isoform of PKC.

Y Goda, C F Stevens and S Tonegawa

Learn. Mem. 1996, 3:

References This article cites 32 articles, 14 of which can be accessed free at: http://learnmem.cshlp.org/content/3/2-3/182.full.html\#ref-list-1

License

Email Alerting

Receive free email alerts when new articles cite this article - sign up in the box at the Service top right corner of the article or click here. 